\title{
Minor congenital ocular anomalies as somatic markers in genetic disorders
}

\author{
Iulia-Andrada Nemes-Dragan, Ana-Maria Dragan, Marius Bembea \\ Faculty of Medicine and Pharmacy, University of Oradea, Romania
}

\begin{abstract}
Introduction. Minor congenital ocular anomalies (MCOA) are important markers for the detection of certain genetic disorders. Even within the same disease, they can vary in their position, numbers or expression intensity. Early detection and diagnosis of genetic disorders are essential to find them and to interpret them correctly and quickly.

Aim. The purpose of this study was to analyse MCOA in genetic diseases, to identify the main types of MCOA as well as to analyze associated genetic disorders.

Material and methods. This is a prospective study of 118 cases presenting with genetic disorders that also presented with MCOA. Its duration was from February 2015 to February 2019. Detailed ocular and adnexa examinations were performed.

Results. Of 118 patients who were enrolled in this study, $84(71 \%)$ had minor ocular anomalies with or without associated major anomalies. Most common MCOA were identified in the eyelid, iris and retina. Down syndrome was the most frequent syndrome associated with MCOA.

Conclusions. Minor congenital ocular abnormalities, even if they are not serious, are often suggestive of certain genetic syndromes. Regardless of the genetic disorders, anatomically, the eyelid is the ocular adnexa that always gives us minor clues of important diagnosis significance.
\end{abstract}

Keywords: ocular anomalies, markers, genetic disorders

\section{INTRODUCTION}

A minor congenital anomaly (MCA) represents any somatic change, of any organ, which does not cause functional disorders, does not have any medical or cosmetical significance and does not need treatment.

The eye is the second most affected organ after the brain, in its frequency of involvement in genetic disorders [1]. The reported global incidence of ocular malformation is 6 per 10,000 births [2]. Ocular genetic diseases or congenital ocular defects are, most often, scattered minor malformations. They are characterized by anatomic changes that involve the morphology of some structures of the eye globe and its adnexa. Their presence at birth can signal a congenital ocular disease.

Ophthalmologists often need to face pathologies with complex symptoms. For this reason, it is impor- tant to perform a detailed examination of these patients, in order to identify other anomalies, as well as to recognize possible specific associations in certain genetic syndromes.

Minor congenital ocular anomalies (MCA) are important markers for the detection of certain genetic disorders. Even within the same disease, they can vary in their position, numbers, or expression intensity [3]. Most MCAs are localized at face and hand level and develop in the initial phase of embryogenesis. A proper analysis must consider the patient's race, ethnicity and family history [4]. Identifying a minor malformation requires all organs that develop during the same embryogenetic period to be examined [5]. For early detection and diagnosis of genetic disorders it is essential to find them and to correctly and quickly interpret them. 


\section{WORKING HYPOTHESIS}

Genetic disorders can be associated with certain specific ocular anomalies. Identification of minor ocular malformations may facilitate the diagnosis of a syndrome.

\section{THE PURPOSE OF THIS STUDY}

The study aimed to analyse MCOA in genetic disorders, having as objectives to identify the main types of MCOA as well as to analyze associated genetic disorders.

\section{MATERIAL AND METHODS}

This is a prospective study of 118 cases presenting with genetic disorders that also presented with MCOA, registered at the Medical Genetic Department of "Gavril Curteanu" City Hospital from Oradea. Its duration was from February 2015 to February 2019. The study was approved by the Ethical Council of the Hospital. Informed parental consent was required for each assessed patient.

The study's inclusion criteria were: all patients with a certain diagnosis of genetic disease, the association in the context of the genetic disease of at least one MCOA, patients that had an ophthalmic assessment performed personally by me or by another specialist.

The study's exclusion criteria were: acquired ocular anomalies and patients with a low degree of compliance.

The ophthalmic assessment included the inspection and slit lamp examination of the ocular adnexa. In each patient the intercanthal and interpupillary distance was measured with a ruler necessary to establish a proper diagnosis of hypertelorism or of telecanthus.

The vertical palpebral height was measured using the cornea superior eyelid index or the pupil superior eyelid margin index.

The anterior eyelid margin, the eyelashes line, and the posterior eyelid margin with the meibomian glands were assessed using a slit lamp. The conjunctiva and the lacrimal system were inspected in a welllighted room and after that through magnification by means of a slit lamp.

The eyeball assessment was performed from anterior to posterior, namely from cornea to retina, first time in miosis and after that in mydriasis.

Before applying mydriatic eyedrops, the direct and consensual pupillomotor reflex, along with the pupilar aperture were assessed.
The iris was analyzed across its entire circumference and thickness. The pupillary margin, the pupillary ruff and the irian periphery were also analyzed.

After applying an eyedrop of Tropicamide 1\% the lens, the posterior pole and the vitreous were examined. The posterior pole exam was performed using Volk 90 diopters lens and a slit lamp when we had good compliance or the ophthalmoscope for less compliance patients (Welch Allyn Panoptic). The optic nerve, macula, the periphery of the macula and retinal vessels were followed from the emergence to the periphery.

\section{RESULTS}

The group includes patients aged between 1 and 65 , coming from rural and urban areas of Bihor County, in fairly equal proportions between males and females.

The majority of patients included in the study, 51 $(43 \%)$, were older than $15,35(30 \%)$ patients were aged between 0 and 7 and 32 patients (27\%) were aged between 7 and 15 .

We examined a number of 118 patients, $74(62 \%)$ were diagnosed with a chromosomal abnormality, 27 $(22 \%)$ with an autosomal dominant disease, 9 cases (7\%) with an autosomal recessive disease and 8 cases $(6 \%)$ with an X-related disease.

Minor ocular malformations are systematized in Table 1.

TABLE 1. Anatomical distribution of minor ocular malformations

\begin{tabular}{|l|c|c|}
\hline Organ & No. & $\%$ \\
\hline Eyelid & & \\
\hline - hypotelorism & 30 & 25 \\
\hline - hypertelorism & 2 & 2 \\
\hline - epicantus & 55 & 47 \\
\hline - ptosis & 2 & 2 \\
\hline - slanted palpebral fissure & 77 & 65 \\
\hline Iris & & \\
\hline Brushfield spots & 19 & 16 \\
\hline Lisch nodules & 5 & 4 \\
\hline Retina & & \\
\hline Spoke-like vessels & 5 & 4 \\
\hline
\end{tabular}

The most common minor ocular abnormalities were present in the ocular adnexa. More precisely, the eyelid was most often malformed. Thus, the most examined patients presented inclined slanted palpebral fissure, 77 (65\%), 50 (47\%) presented epicanthus, $30(25 \%)$ presented hypotelorism, 2 patients $(2 \%)$ presented with ptosis and $2(2 \%)$ hypertelorism. The most commonly affected ocular structure that gave us minor clues for diagnosis was the iris. The 
vast majority of patients, 99 (84\%) had dark colored irises. Brushfield's spots were present in 19 patients (16\%) and Lisch's nodules in 5 cases (4\%) (Figure 1).
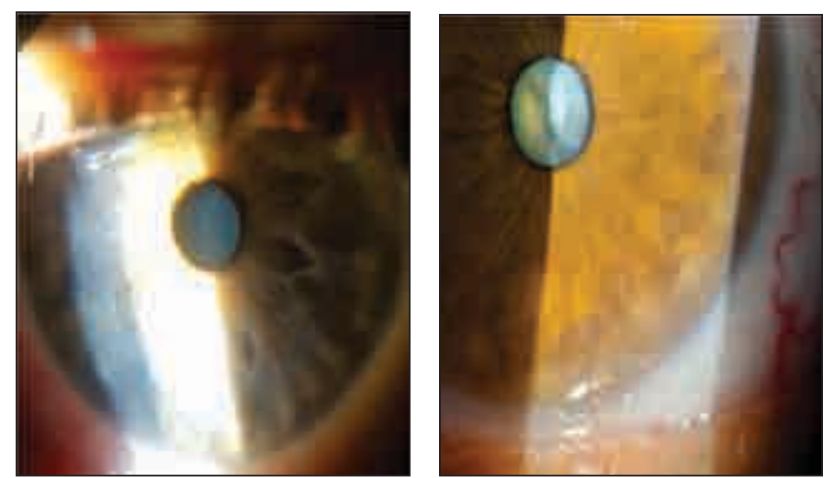

A

B

FIGURE 1. Minor iris malformations. A. Brushfield's spots. $B$. Lisch's nodules

Examination of the posterior pole revealed 5 patients (4\%) with supranumerary vessels, with a "spoke-like" appearance.

Out of a total of 118 patients, $84(71 \%)$ presented minor malformations with or without major associated malformations. Thus, 19 (16\%) patients with a single minor malformation were examined, 34 (29\%) patients with 2 minor malformations and 31 (26\%) patients with 3 or more minor congenital anomalies. (Table 2)

The distribution of patients according to genetic syndrome was: most patients, 73 (86\%), with minor ocular abnormalities presented with Down syndrome, 7 patients with type 1 neurofibromatosis ( $8 \%), 2$ patients $(2 \%)$ with blepharophimosis syndrome, 1 patient (1\%) with Schwartz-Jumpel syndrome and 1 (1\%) with congenital extraocular muscle fibrosis.

TABLE 2. Frequency of association of minor ocular malformations

\begin{tabular}{|l|c|c|}
\hline Minor malformations & $\begin{array}{c}\text { Number of } \\
\text { patients }\end{array}$ & $\%$ \\
\hline 1 minor malformation & 19 & 16 \\
\hline 2 minor malformations & 34 & 29 \\
\hline$\geq 3$ minor malformations & 31 & 26 \\
\hline Total & 84 & $71 \%$ \\
\hline
\end{tabular}

\section{DISCUSSION}

The eye examination should be performed starting from 6 months or even from birth when it can make a significant contribution to the diagnosis of a genetic syndrome or a disease. It is obvious that studying objective markers that facilitate a faster diagnosis for the clinician and reduce the vision-threatening complication is needed [6].
The age group of 15 and over was best represented $(43 \%)$ because it is also the age at which the compliance and addressability of patients with genetic disease and their relatives increases. The result was similar to those presented in the literature by Schneider et al. [7] and Collins et al. [8]. Chuka-Osaka and colleagues stated in a study of patients with both minor and major ocular abnormalities that the severity of the malformations influences the age of diagnosis of congenital ocular abnormalities [9].

The most common genetic syndrome present in the study was Down syndrome, which is also the most common genetic chromosomal abnormality, globally [10-12]. The result is consistent with the study conducted by Bermejo and Martinez-Frias [13], where the large number of ocular abnormalities was due to a large number of cases of trisomy 21 .

Minor or simple ocular abnormalities were also present in a large number of patients in the study by Marzouk et al. [14].

The current study revealed that minor eye abnormalities were multiple in $71 \%$ of cases, a result of great practical value. Thus, whenever a minor anomaly is identified, it is necessary to look for others.

Eyelid malformations are diagnostic criteria for trisomy 21. Given the large number of patients with this chromosomal abnormality, the eyelid was the universally affected ocular adnexa in all studies performed on these patients $[15,16]$. The study conducted by Arora and collaborators also showed that anatomically, palpebral and positional malformations are the most common ocular abnormalities [17]. The abnormalities present at this level are minor abnormalities but of great utility for the diagnosis of the syndrome.

Slanted palpebral fissures are the most common abnormality in patients with Down syndrome present both in our study and in most studies [18]. The incidence of this anomaly in the current study was slightly lower compared to the one found by Scherbenske et al., $65 \%$ vs. $80 \%$ [19].

The ocular component that showed the most changes was the iris. Morrison described in his study the importance of examining the iris in genetic pathology. He noted that a thorough examination of it could be a window into the most common and rare genetic diseases [20].

In 1924, Brushfield found concentric white spots on the edge of the iris of Down syndrome patients that had light colored irises. Their prevalence in the current study was $16 \%$, a result that is in concordance with studies performed in Asia or on a large sample of patients with dark colored irises [21,22].

Postolache et al. stated that examining a dark colored iris using infrared light increases their detec- 
tion rate from $21 \%$ for those examined with white light all the way up to $65 \%$ [23].

Lisch nodules were present in 5 out of 7 patients presenting with an autosomal dominant disease. As opposed to Brushfield spots which were discovered by Wölfflin in patients that didn't present with any genetic disease, Lisch nodules are pathognomic and present in $90 \%$ of adults diagnosed with type I neurofibromatosis [24,25].

The presence of supranumerary vessels or spokelike vessels is a minor abnormality present in patients with Down syndrome. Williams and colleagues were the first to mention in 1973 the presence of an increased number of vessels at the level of the optical disc in Mongols [26]. The presence of this minor malformation was also certified by Sherk et al., who added that it is present independently of cardiac pathology [27].

\section{REFERENCES}

1. Costa T, Scriver R.C, Childs B. The Effect of Mendelian Disease on Human Health: A Measurement. American Journal of Medical Genetics. 1985;21:231-242.

2. Traboulsi E. Genetic Diseases of the Eye. 2nd Edition. Oxford University Press 2012:190-245.

3. Bembea M. Genetica în pediatrie. Cluj-Napoca. Risoprint, 2016:97-113.

4. Askin DF. Physical assessment of the newborn: minor congenital anomalies. Nurs Womens Health. 2009;13(2):140-8.

5. Adam M, Hudgins $L$. The importance of minor anomalies in the evaluation of the newborn. NeoReviews. 2003;4(4):e99-104.

6. Tomairek RH, Amin MM, Raafat K, Abdel Hady S, Elkotoury A. Prevalence of Congenital Ocular Anomalies among Children with Genetic Disorders: An Egyptian Study. Semin Ophthalmol. 2018; 33(5):613-619.

7. Schneider KI, Schimdtke J. Patient Compliance Based on Genetic Medicine: A Literature Review. J Community Genet. 2014;5(1):31-48.

8. Collins RE, Wright AJ, Marteau TM. Impact of communicating personalized genetic risk information on perceived control over the risk: a systematic review. Genet Med. 2011;13(4):273-7.

9. Chuka-Okosa CM, Magulike NO, Onyekonwu GC. Congenital eye anomalies in Enugu, South-Eastern Nigeria. West Afr J Med. 2005; 24(2):112-4.

10. Kazemi M, Salehi M, Kheirollahi M. Down Syndrome: Current Status, Challenges and Future Perspectives. Int J Mol Cell Med. 2016; 5(3):125-133.

11. Murthy SK, Malhotra AK, Mani S, Shara ME, Al-Rowaished EE, Naveed S, Alkhayat Al, Alali MT. Incidence of Down syndrome in Dubai, UAE. Med Princ Pract. 2007;16(1):25-8.

12. Malt EA, Dahl RC, Haugsand TM, Ulvestad IH, Emilsen NM, Hansen B, Cardenas YE, Skøld RO, Thorsen AT, Davidsen EM. Health and disease in adults with Down syndrome. Tidsskr Nor Laegeforen. 2013;133(3):290-4.

13. Bermejo E, Martínez-Frías ML. Congenital eye malformations: clinical-epidemiological analysis of 1,124,654 consecutive births in Spain. Am J Med Genet. 1998;75(5):497-504.

14. Marzouk IM, Elshakankiry NM, Ibrahim AG, Anwar SAM, Awadallah SM. Registry of ocular anomalies among patients with genetic
Pursa et al. found that the presence of supranumerary vessels is a protective factor for angiogenesis in the cases of diabetic retinopathy or solid tumor Down patients. This particularity is caused by an increased level of endostatine, a coded protein of chromosome 21, that inhibits angiogenesis [28].

\section{CONCLUSIONS}

Minor congenital ocular abnormalities, even if they are not serious, are often suggestive of certain genetic syndromes. Their detection must be included in the diagnostic protocol of any suspected genetic disorder. Regardless of the genetic disorders, anatomically, the eyelid is the ocular adnexa that always gives us „minor“ clues of important diagnosis significance.

\section{Conflict of interest: none declared Financial support: none declared}

disorders in Alexandria and nearby governorates. Alexandria Journal of Pediatrics 2019;32(1):55-60.

15. Kim JH, Hwang JM, Kim HJ, Yu YS. Characteristic ocular findings in Asian children with Down syndrome. Eye (Lond). 2002;16(6):710-4.

16. Caputo AR, Wagner RS, Reynolds DR, Guo SQ, Goel AK. Down syndrome. Clinical review of ocular features. Clin Pediatr (Phila). 1989; 28(8):355-8

17. Arora P, Tullu MS, Muranjan MN, Kerkar SP, Girisha KM, Bharucha BA. Congenital and inherited ophthalmologic abnormalities. Indian J Pediatr. 2003;70(7):549-52.

18. Eissler R, Longenecker LP. The common eye findings in mongolism. Am J Ophthalmol. 1962;54:398-406.

19. Scherbenske JM, Benson PM, Rotchford JP, James WD. Cutaneous and ocular manifestations of Down syndrome. J Am Acad Dermatol. 1990;22(5Pt2):933-8.

20. Morrison PJ. The iris - a window into the genetics of common and rare eye diseases. Ulster Med J. 2010;79(1):3-5.

21. Fimiani F, lovine A, Carelli R, Pansini M, Sebastio G, Magli A. Incidence of ocular pathologies in Italian children with Down syndrome. Eur J Ophthalmol. 2007;17(5):817-22.

22. Fong AH, Shum J, Ng AL, Li KK, McGhee S, Wong D. Prevalence of ocular abnormalities in adults with Down syndrome in Hong Kong. $\mathrm{Br}$ J Ophthalmol. 2013;97(4):423-8.

23. Postolache, L, Parsa, CF. Brushfield spots and Wölfflin nodules unveiled in dark irides using near-infrared light. Sci Rep. 2018;8:18040.

24. Daoudi C, Daoudi R. Lisch nodules in Von Recklinghausen disease. Pan Afr Med J. 2014;19:173.

25. Maharaj A, Singh VR, Lalchan SA. Lisch and the Importance of His Nodules. West Indian Med J. 2014;63(7):799-802.

26. Williams EJ, McCormick AQ, Tischler B. Retinal vessels in Down's syndrome. Arch Ophthalmol. 1973;89(4):269-71.

27. Sherk MC, Williams TD. Disc vascularity in Down's syndrome. Am J Optom Physiol Opt. 1979;56(8):509-11.

28. Parsa CF, Almer Z. Supranumerary optic disc vessels may indicate reduced systemic angiogenesis in Down syndrome. $\mathrm{Br} \mathrm{J}$ Ophthalmol. 2008;92(3):432-3. 